\title{
Expectancy waves and other complex cerebral events in dyslexic and normal subjects'
}

\section{B. FENELON, The University of Newcastle, N.S.W., Australia}

Slow cortical waves were studied in a small group of adult and child $S$ s. A peculiarity in the brain response under conditions, of uncertainty was noted. Cerebral responses of dyslexics to semantic stimuli differed from those of normal Ss. A reinterpretation of slow positive waves is suggested, and proposals are made for the study of complex brain responses under varying conditions of arousal and set. especially in relation to remedial programs for dyslexic children.

Pilot studies of brain responses to semantic stimuli. including Contingent Negative Variation (CNV) or Expectancy Waves (E-waves), which were first described by Walter (1964), were carried out by Cohen, Offner, \& Blatt (1965) on normal children and a small group of Dyslexics. Responses to words and pictures were found to be more complex than responses to tones or flashes of light. As a group, dyslexic Ss developed al CNV to flash, sound, and key-pressing, but tended not to show the response to a sound preceding the presentation of different words on a screen. The E-waves of dyslexic children in anticipation of pictures were of less than usual magnitude. The most outstanding feature of the dyslexic records was a positive wave of high amplitude and long duration which followed the presentation of visual semantic stimuli. A CNV normally developed when pictures were preceded by sounds, and a further medium-latency negative wave appeared in the averaged record when pictures were changed for each cycle of the averager. This wave was interpreted as a response to the diversity of the situation.

One aim of the present study was to investigate the course of habituation of the CNV in the classical physical stimulus contingency situation. A further aim was to investigate the nature of the cortical response to semantic stimuli in dyslexic and normal Ss. Wyke (1961) presented evidence that aphasic deficit is in large part attributable to disruption of associative processes. Consonant-vowel-consonant (CVC) trigrams were, therefore, included among the semantic stimuli, and it was hypothesized that normal children of reading age would demonstrate CNVS to the trigrams on the basis of their associative significance while dyslexic children would show a lesser reaction.

Apparatus

One amplifier of a 16-channel Elema-Schönander EE(; was linked via an analog-digital converter to al pulse-height analyzer modified to act as a bioelectric signal averager. ${ }^{3}$ The on-line computer of this system carried out a 400-data-point analysis over a preset time interval, after being triggered by an external pulse supplied from the interval timer which initiated the first stimulus (SI) in each trial. The averaged record was displayed visually on the CRO of an oscilloscope, and permanent records of the trace were secured as desired with an oscilloscope camera.

Standard silver-silver chloride scalp electrodes were secured by a rubber headcap. Midline electrodes were referred to the right mastoid, and individual electrode pairings were given preliminary trials. Vertex potentials from the $\mathrm{Cz}$ electrode. slightly anteriorly placed, were selected for analysis. EEG recordings were taken at a frequency response of $30 \mathrm{~Hz}$ on the maximum time constant of 1.2 sec. Sensitivity was varied as required, but most recordings were taken at 100 microvolts. The CRO trace was measured against a 100 microvolts calibration signal from the EEG, which produced a $4 \mathrm{~mm}$ deflection in an electro-negative direction.
Pure tones were generated by an andio-frequency oscillator, with output level governed by a decale attenuator. Tones were delivered to the $S$ binaurally through $10 \mathrm{ohm}$ impedance stereo-type headphones. Single tlaslies were provided by a photo-stimulator set at a distance approximately $60 \mathrm{~cm}$ from the $S$, at a horizontal angle of approximately $30 \mathrm{deg}$. Semantic stimuli were back-projected to a milk-glass screen placed approximately $2 \mathrm{~m}$ from the $S$. The screen was supported in a mobile metal framework which was moved into place surrounding the $S$. The framework was draped with blackout curtaining and served as a miniature isolation environment.

A bank of three interval timers actuated the signalling equipment and provided the necessary stimulus schedules. Subjects

Four young adults and four children were submitted to a variety of experimental procedures. Two dyslexic and two normal children were selected. All children attended State Public Primary Schools. Dyslexia was diagnosed on the basis of unconflicting case history. scholastic. psychometric, and speech therapy evidence.

\section{Classical CNV \\ PROCEDURE AND RESULTS}

To evoke the classical CNV. a single flash ( $\mathrm{S}$ ) was followed after 1 sec by a $1000 \mathrm{cps}$ tone (S2) of mildly unpleasant intensity. The $S$ was told to attempt to cut the duration of the tone by depressing a signal key mounted on the chair arm. Rapid reactions were urged with a warning that false (early) responses were detectable. No such responses occurred. The computer was set to scan a 1.2-sec interval. The classical CNV was observable in the usual form with two of the adult Ss. A third $S$ failed to show a CNV under normal stimulus conditions. The fourth $S$ exhibited a most interesting pattern of response under conditions of technical failure, when the intensity of S2, the auditory stimulus which acted as an imperative signal, was greatly attenuated and almost inaudible. unknown to the $E$. In the second series of trials, which were actually unreinforced. the tentative CNV at 0.5 sec was reduced in size. The second negative component was much lower in amplitude, as it expectancy was reluced. Under the circumstances, habituation should have been taking place. In the third series of trials, reinforcement was reinstituted. and the signal was probably vaguely and uncertainly detectable by the $S$ in contrast with the real silence of the second series. The E-wave of the interstimulus interval showed some small increase in amplitule, the positive wave complex was virtually eliminated, and the second negative component increased considerably in amplitude and stability. It might well be interpreted as a "perplexity" wave, a form of an E-wave to the total stimulus situation.

CVC Series

For the consonant-vowel-consonant series, trigrams ( $\left.S_{2}\right)$ were presented serially, following $S 1$ (light flash). Adult Ss were instructed to find word associates as quickly as possible. Children were instructed that they were to view words that were not quite words, and that they were to try to think of similar, but real, words as quickly as possible. The computer scanned a 4-sec interval. The essential features of the average traces for two child Ss are shown in Fig. 1. In incluiry, it was ascertained that the two normal children matched words to the trigrams in some instances. The younger child reported words similar in appearance to three of the stimuli; the elder child reported actual associates (in some cases multiple associates) and expansions to the majority of the stimuli. The 


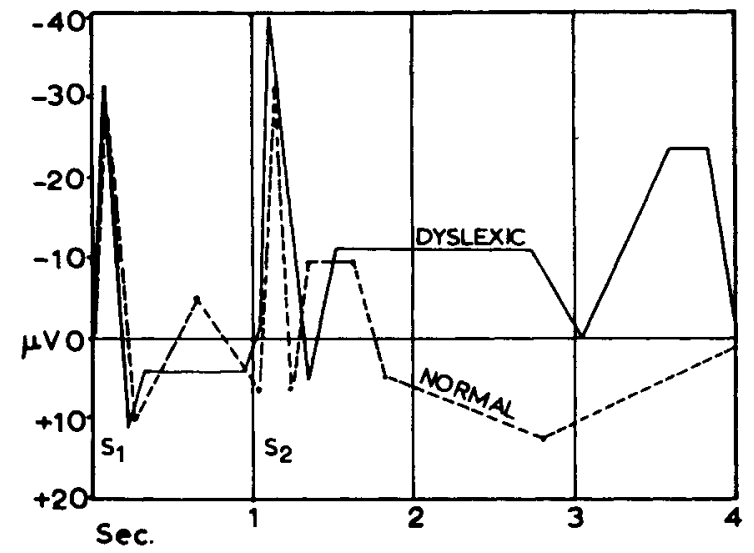

Fig. 1. Principal features of average trace of six-year-old Ss after 15 trials in CVC series.

dyslexic children appeared not to experience such verbal associations.

With one of the normal children, a surplus arousal procedure was used in a second CVC series. Tactile stimulation $4 \mathrm{~V}$ above threshold level was applied through a vibrator attached to the mesial surface of the forearm. Stimulation commenced coincident with $S 1$ and continued $0.5 \mathrm{sec}$ after S2. In this case, the E-wave disappeared, as if the $S$ had lost the association between $\mathrm{S} 1$ and S2. A third evoked response appeared on discontinuation of vibration, followed by a very large amplitude positive wave. At the end of a 3 -sec period, there seemed to be an E-wave in expectancy of the onset of further vibrotactile stimulation.

\section{Classical CNV}

\section{DISCUSSION}

The three habituation series for the adult $S$ when the signalling apparatus failed show, through an accident of technique, some aspects of the brain response to conditions of uncertainty, which might otherwise not have been observed. By the end of the second series habituation of cortical response was well advanced. Had the $S$ been unable to detect any difference between the second and the third series, the habituation process whould have gone on to completion. This interpretation is based on evidence concerning rate of habituation in nonconditioning situations. The signal was, however, detectable in the third series, though uncertainly, and a stable high-amplitude negative wave takes up more than half of the trace. It is as if perplexity had supervened over the extinction process and led to a suspension of other aspects of cortical activity.

The latency, stability, and duration of this wave add to the arguments already offered by other workers (e.g., by Cohen et al, 1965) that E-type waves are of cerebral origin. Galvanic skin response and eye movements must be discounted as possible sources of artifact, and myographic responses of the amplitude and long duration recorded are similarly unlikely.

CVC Series

The six-year-old dyslexic child developed no E-wave in the S1-S2 interval. The temporal association of the two stimuli, and the contingency involved, produced no expectancy in the child, as if verbal stimuli held no meaning or significance. In the post-S2 interval, a positive component is totally lacking, which may be interpreted as an indication of continuing general expectancy, already indicated in the large post-S2 negative wave. It would seem advisable to think of the slow positive components in ternns of cortical inhibition or concentration concepts, a phase which represents resolution of expectancy and perhaps associative activity.

These records of the six-year-old normal and the eight-year-old dyslexic are similar and may perhaps be regarded as developmentally equivalent. They differed markedly from the records of the eight-year-old normal child and the adult, and also from that of the six-year-old dyslexic. This suggests that the interpretations of Cohen et al (1965) of the nature of the dyslexic cortical response may be too general, and that age level requires taking into account.

It is planned to study the effects of varying levels of arousal on E-waves, and to investigate the effects of mental set, particularly divided vs uniform set. These studies will be conducted on normal and dyslexic children and related to actual learning performances of such children. At present the learning potential of dyslexic children is guessed at from inadequately defined indicators in psychological tests, and teaching regimes of a remedial type are organized largely on a blindly empirical basis. It seems basic to a rational method of treatment of retarded language-development cases and dysphasics to attempt to understand the actual cerebral responses in model learning situations.

\section{REFERENCES}

COHEN, J., OFFNER, F., \& BLATT, S. Psychological factors in the production and distribution of the Contingent Negative Variation (CNV). Communicationes (sic) of the 6th International Congress of Electroencephalography and Clinical Neurophysiology, Vienna, Sept. 5-10, 1965 .

WALTER, W. G. Slow potential waves in the human brain associated with expectancy, attention and decision. Archiv für Psychiatrie und Zeitschuift für die gesamte Neurologie, 1964, 206, 309-322.

WYKE, M. Experimental study of verbal association learning in patients with severe dysphasia. Journal of Neurology, Neurosurgery, and Psychiatry, 1966, 29, 171-175.

\section{NOTES}

1. The author acknowledges with thanks the technical assistance of Miss Christine Johnston and Messrs. R. Hodge and H. Norrie.

2. Thanks are due to Dr. E. Currow, Medical Superintendent, Royal Newcastle Hospital, for facilities provided by the hospital to carry out this study.

3. Nuclear-Chicago, Model 3427 , supplied by courtesy of Sample Electronics, Alexander Street, North Sydney. 